\title{
Противодействующий фотовольтаический эффект в верхней межгенераторной части трехпереходных GalnP/GaAs/Ge солнечных элементов
}

\author{
(C) М.А. Минтаиров, В.В. Евстропов, С.А. Минтаиров, М.З. Шварц, Н.А. Калюжный \\ Физико-технический институт им. А.Ф. Иоффре Российской академии наук, \\ 194021 Санкт-Петербург, Россия \\ E-mail: mamint@mail.ioffe.ru
}

Поступила в Редакцию 13 июня 2019 г.

В окончательной редакции 21 июня 2019 г.

Принята к публикации 21 июня 2019 г.

Проанализирован „верхний“ межгенераторный участок, расположенный между GaInP и GaAs субэлементами (генераторами электрической энергии). Проанализированы форма световых вольт-амперных характеристик и зависимость $V_{o c}-J_{s c}$ (напряжение холостого хода-ток короткого замыкания). Установлено, что туннельный гетеро- $p^{+}-n^{+}$-переход, расположенный в „верхней“ межгенераторной части, может работать в качестве фотоэлектрического источника, противодействующего базовым $p-n$-переходам. В этом случае $V_{o c}-J_{s c}$-характеристика имеет падающий участок, в том числе может наблюдаться резкий скачок. Этот нежелательный эффект уменьшается при увеличении пикового тока туннельного перехода.

Ключевые слова: многопереходный солнечный элемент, концентрированное солнечное излучение, фотовольтаические характериыстики, вольт-амперные характеристики, встречная электродвижущая сила, туннельный диод.

DOI: $10.21883 /$ FTP.2019.11.48457.9190

\section{1. Введение}

Tрехпереходные $\mathrm{GaInP} / \mathrm{GaAs} / \mathrm{Ge}$ солнечные элементы (СЭ) активно используются в космической и концентраторной фотовольтаике. Разрабатываются четырех-, пятии шестипереходные СЭ [1-3]. Основным достоинством различных видов многопереходных (МП) СЭ является увеличение эффективности преобразования солнечной энергии в электрическую, так как добавление каждого фотовольтаического перехода расширяет диапазон спектральной чувствительности прибора, способствуя увеличению эффективности.

При увеличении числа фотовольтаических $p-n$-переходов (генераторов электрической энергии) увеличивается количество соединительных участков, в том числе количество межгенераторных участков. В таких межгенераторных участках в качестве соединительных элементов обычно используются туннельные $p^{++}-n^{++}$-переходы, так как они могут обеспечить малое соединительное сопротивление при выполнении определенных условий, иногда трудно выполнимых. Отметим, что туннельные $p^{++}-n^{++}$-переходы включены последовательно и встречно по отношению к базовым фотовольтаическим $p-n$-переходам, что создает возможность возникновения встречного (противодействующего) фотовольтаического эффекта. Существование такого эффекта в трехпереходных $\mathrm{GaInP} / \mathrm{GaAs} / \mathrm{Ge} \mathrm{C} \ni$ предполагалось нами ранее [4] для интерпретации экспериментальных характеристик: напряжение холостого хода $\left(V_{o c}\right)$-фотогенерированный ток $\left(J_{g}\right)$. Основание для такого предположения - аномалия: максимум на
$V_{o c}-J_{g}$-характеристике или по крайней мере тенденция к его образованию. Такая аномалия наблюдалась ранее в ряде экспериментов $[5,6]$. Внешне она похожа на эффект нагрева СЭ падающим излучением. Поэтому была разработана процедура получения изотермической $V_{o c}-J_{g}$-зависимости [7]. Было установлено, что эффект нагрева следует учитывать (с погрешностью менее $1 \%$ ), только если кратность солнечного излучения $X$ больше 2000 крат [7]. Между тем в процессе поисковоисследовательской работы по оптимизации трехпереходных GaInP/GaAs/Ge CЭ были получены образцы двухпереходных $\mathrm{GaInP} / \mathrm{GaAs} \mathrm{CЭ}$, в которых указанная аномалия наблюдалась при кратностях $X$, заметно меньших 2000 крат. Свойство этой аномалии исследовано в данной работе. Показано, что противодействующий фотовольтаический эффект действительно возникает в трехпереходных $\mathrm{GaInP} / \mathrm{GaAs} / \mathrm{Ge} \mathrm{C}$ Э. Причем в определенных случаях этот эффект может быть значительным.

В данной работе установлено, что источник этого фотовольтаического эффекта расположен в „верхнем“ межгенераторном участке, т. е. между „верхним“ GaInP и „средним“ GaAs фотовольтаическими $p-n$-переходами. Этот источник - туннельный гетеро- $p^{+}-n^{+}$-переход $p^{+} \mathrm{Al}_{0.4} \mathrm{Ga}_{0.6} \mathrm{As}(\mathrm{C}) / n^{+} \mathrm{GaAs}(\mathrm{Si})$. Он способен генерировать электродвижущую силу(эдс), разделяя электроннодырочные пары, которые могут инжектироваться в $p^{+}-n^{+}$-переход путем поглощения света в самом $p^{+}-n^{+}$-переходе (фотоинжекция) или путем диффузии носителей из соседнего прямосмещенного фотовольтаического $p-n$-перехода (диффузионная инжекция). Среди изготовленных поисково-исследовательских 
образцов выделены такие, у которых высота горба на темновой вольт-амперной характеристике (BAX) туннельного $p^{+}-n^{+}$-перехода практически отсутствует, т.е. реализуется предельный случай туннельного $p^{+}-n^{+}$-перехода - обращенный $p-n$-переход. Противодействующий фотовольтаичекий эффект в этом случае значительно усиливается. Таким образом, исследование характеристик двухпереходных $\mathrm{GaInP} / \mathrm{GaAs} \mathrm{CЭ}$ позволило установить источник возникновения противодействующей эдс, а также определить его влияние на фотовольтаические характеристики МП СЭ. Это влияние схоже с тем, которое наблюдалось ранее на трехпереходных GaInP/GaAs/Ge CЭ [8]. Как в тех CЭ, так и в исследуемых в данной работе двухпереходных СЭ верхний межгенераторный участок (между $p-n$-GaInP и $p-n$-GaAs) создавался аналогичным способом.

\section{2. Объекты исследования}

Bce анализируемые двухпереходные GaInP/GaAs CЭ были выращены методом металлорганической газофазной эпитаксии (МОГФЭ). Среди анализируемых выделены три образца, которые наиболее явно указывают на локацию источника противодействующего фотовольтаического эффекта.

На рис. 1 показаны три конструкции межгенераторной части (справа) и соответствующие энергетические зонные диаграммы (слева). У образца $A$ (рис. 1, $a$ ) межгенераторная часть близко совпадает с „верхней“ межгенераторной частью трехпереходного $\mathrm{GaInP} / \mathrm{GaAs} / \mathrm{Ge}$ СЭ, анализировавшегося в работе [8]. Туннельный гетеро- $p^{+}-n^{+}$-переход формировался единообразно: во всех случаях выращивалась $p^{+}-\mathrm{Al}_{0.4} \mathrm{Ga}_{0.6} \mathrm{As}(\mathrm{C})$-область, легированная углеродом до концентрации $p^{+} \approx$ $\approx 1.5 \cdot 10^{19} \mathrm{~cm}^{-3}$, и $n^{+} \mathrm{GaAs}(\mathrm{Si})$-область, легированная кремнием до концентрации $n^{+} \approx(5-7) \cdot 10^{18} \mathrm{~cm}^{-3}$. Конструкции межгенераторных частей (рис. 1, фигурные скобки) незначительно отличались.

Межгенераторная часть образца $A$ имеет структуру, типичную для трехпереходных СЭ. В образце $B$ $n$-область не вырождена, $n<5 \cdot 10^{18} \mathrm{~cm}^{-3}$ (рис. $1, b$, кружок), поэтому, как отмечено в разд. 4.2, горб на ВАХ $p^{+}-n$-перехода не наблюдается. В этом случае $p^{+}-n$-переход почти туннельный, т. е. обращенный. У образца $C$, в отличие от $A$ и $B$, отсутствует широкозонный барьер (рис. 1, $c$, окрестность левой пунктирной вертикальной линий). Такое отсутствие барьера облегчает диффузионную инжекцию электронно-дырочных пар в туннельный $p^{+}-n$-переход из базового фотовольтаического GaInP $p-n$-перехода (разд. 4.3).

В работе исследовались фотовольтаические характеристики СЭ, основанные на измерении ВАХ. Для всех измерений использовался импульсный имитатор солнечного излучения. Установка оснащена устройствами контроля освещенности и температуры образца и четырехзондовой системой измерения ВАХ. Регистрация пи-
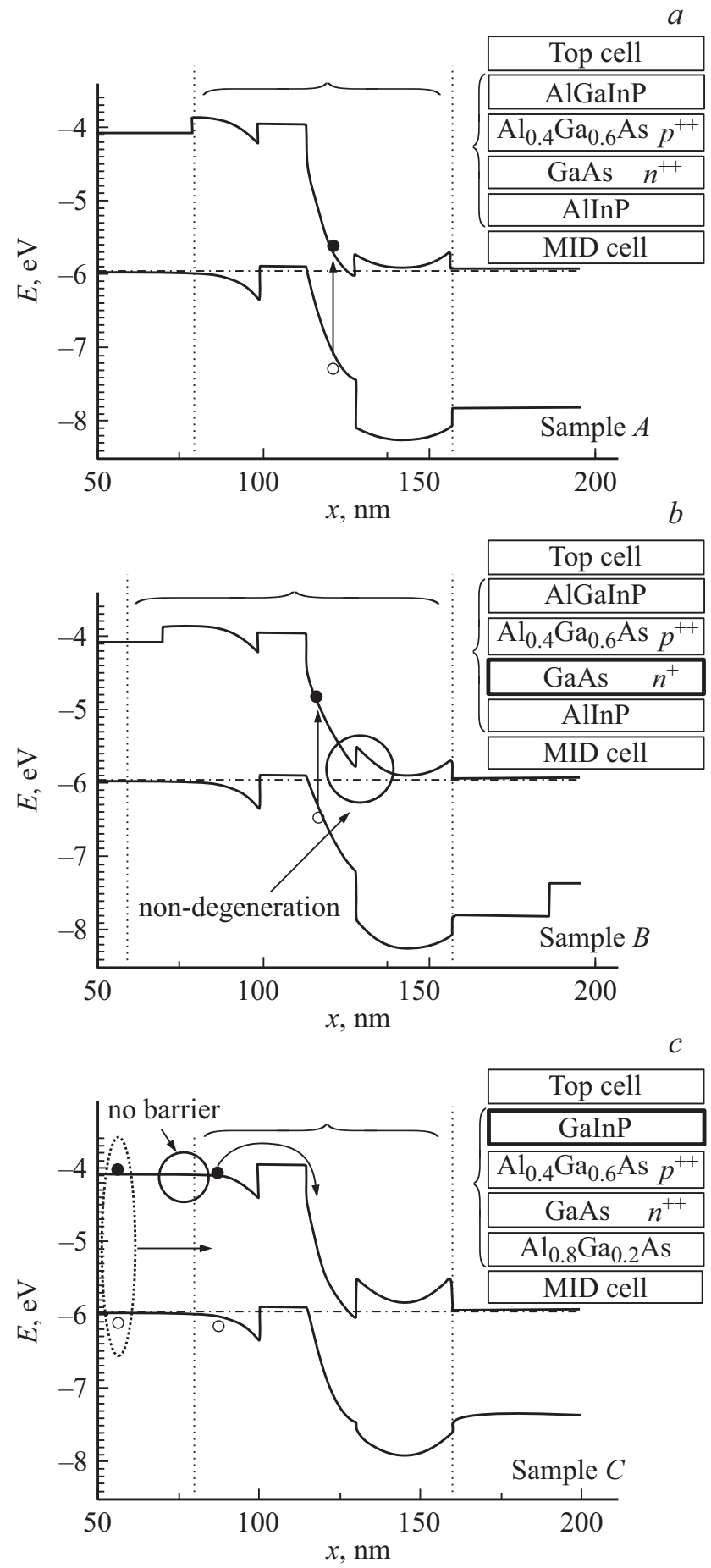

Рис. 1. Конструкции (справа) и соответствующие энергетические диаграммы межгенераторной части (слева) трех видов двухпереходных $\mathrm{GaInP} / \mathrm{GaAs} \mathrm{C}$. Для образца $A$ конструкция близко совпадает с соответствующей конструкцией межгенераторной части типового трехпереходного $\mathrm{GaInP} / \mathrm{GaAs} / \mathrm{Ge}$ СЭ. Энергетические зонные диаграммы получены по модели, описанной в [9].

кового тока туннельных $p^{+}-n^{+}$-переходов проводилась при развертке напряжения в сторону его уменьшения. Максимальная кратность 10000 крат. 


\section{3. Получение ВАХ верхней межгенераторной части}

Три набора экспериментальных световых ВАХ для каждого образца $(A, B, C)$ приведены на рис. 2 (правые части графиков, положительные напряжения, символы). Каждая кривая имеет напряжение холостого хода $\left(V_{o c}\right)$ и ток короткого замыкания $\left(J_{s c}\right)$, который для ВАХ данной формы равен фотогенерированному току $J_{s c}=J_{g}$. Следовательно, можно получить три $V_{o c}-J_{g}$-зависимости, соответствующие трем образцам $A$, $B, C$. Чтобы исключить влияние нагрева на форму этих зависимостей, другими словами, чтобы получить изотермические $V_{o c}-J_{g}$-кривые была применена процедура, описанная в [7]. Три полученные изотермические $V_{o c}-J_{g}$-зависимости показаны на рис. 3. Линейные (в полулогарифмическом масштабе) участки аппроксимированы двухэкспоненциальной моделью

$$
J_{g}=J_{02} \exp \left(\frac{V_{o c}}{2 k T}-1\right)+J_{03} \exp \left(\frac{V_{o c}}{3 k T}-1\right),
$$

где свободные параметры (предэкспоненты) $J_{02}=$ $=8.0 \cdot 10^{-25} \mathrm{~A} / \mathrm{cm}^{2}, \quad J_{03}=5.5 \cdot 10^{-16} \mathrm{~A} / \mathrm{cm}^{2}$. Штриховая линия на рис. 3 , описываемая формулой (1), - это нормализованная (изотермическая и без противодействующего фотовольтаического эффекта) $V_{o c}-J_{g}$-характеристика, которая эквивалентна темновой нормализованной (изотермической безрезистивной) ВАХ при формальной замене $V_{o c}=V, J_{g}=-J$. Отметим, что нормализованная характеристика одинакова для всех трех образцов (рис. 3, штриховая линия). Из темновой нормализованной BAX сформирован набор световых BAX путем токового сдвига на такие значения $J_{g}$, которые есть у набора экспериментальных световых BAX. Этот набор (рис. 2, сплошные линии) выполняет роль референсных характеристик по отношению к экспериментальным световым ВАХ, так как он не включает резистивные потери и противодействующий фотовольтаический эффект. На рис. 2 изображены, кроме того, экспериментальные световые ВАХ (правая часть, символы). Искомые световые BAX межгенераторной части (рис. 2, левая часть, символы) получены путем вольтового вычитания референсных ВАХ из экспериментальных. Каждая экстрагированная таким способом искомая ВАХ представляет собой вольтовую сумму световой $\mathrm{BAX}$ туннельного $p^{+}-n^{+}$-перехода и $\mathrm{BAX}$ резистивного участка межгенераторной части.

\section{4. Сравнение межгенераторных частей}

На рис. 2, $a-c$ видно, что с увеличением освещенности BAX межгенераторной части для всех образцов смещаются в противоположном (вниз) направлении по отношению к смещениям (вверх) ВАХ базовых $p-n$-переходов. Это свидетельствует о том, что межгенераторная часть всех образцов фотоактивна. В отсутствие
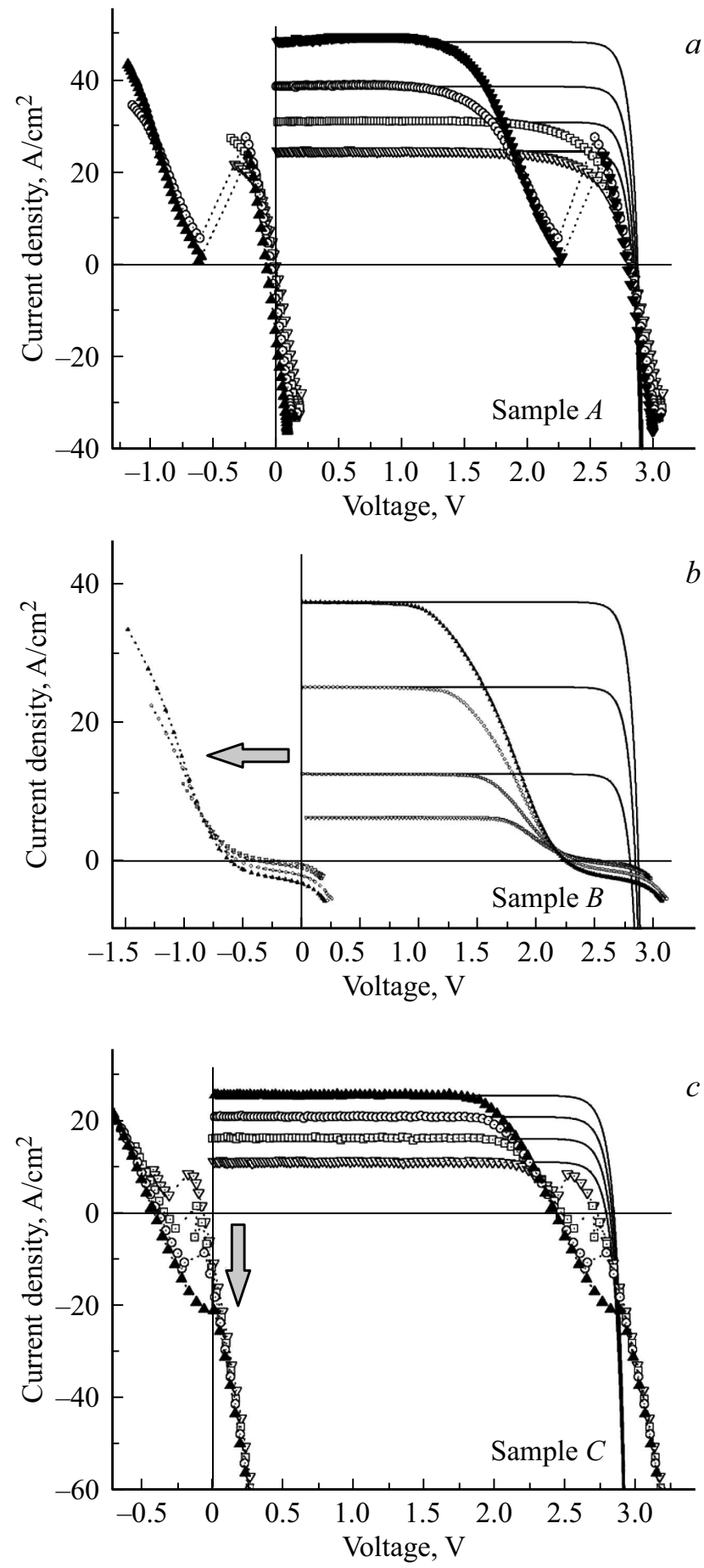

Рис. 2. Световые ВАХ для трех видов двухпереходных $\mathrm{GaInP} / \mathrm{GaAs} \mathrm{CЭ}$ (справа от оси токов) и для трех соответствующих межгенераторных участков (слева от оси токов); сплошные линии - BAX, сформированные из нормализованной $V_{o c}-J_{g}$-характеристики (рис. 3 , штриховая линия), символы экпериментальные ВАХ (справа) и экстрагированные из них BAX межгенераторной части (слева).

дополнительной (диффузионной) инжекции носителей (образцы $A$ и $B$ ) встречный фотогенерированный ток определяется только поглощением фотонов в туннель- 


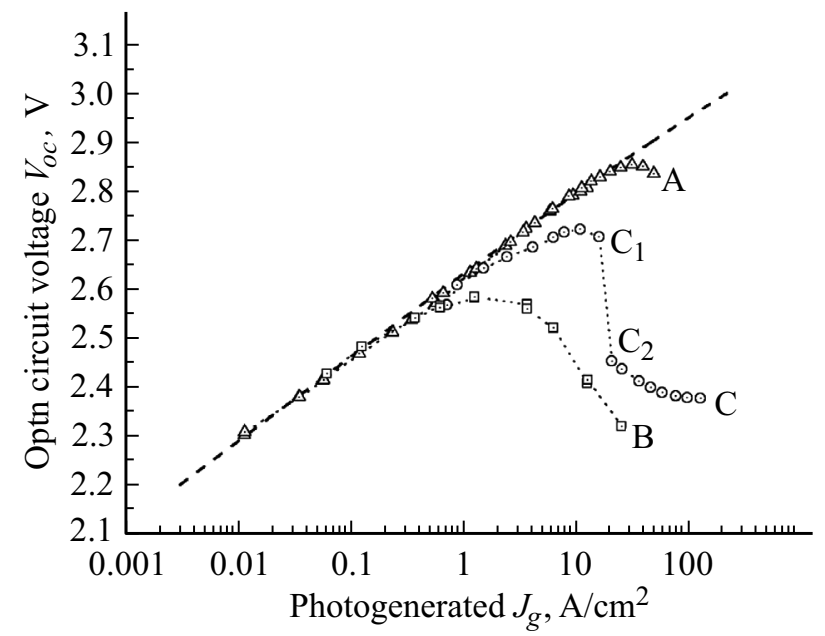

Рис. 3. Экспериментальные $V_{o c}-J_{g}$-зависимости (символы) для трех видов двухпереходных $\mathrm{GaInP} / \mathrm{GaAs}$ CЭ. Штриховая линия, описываемая формулой (1), - это нормализованная $V_{o c}-J_{g}$-зависимость. Экспериментальные вольтовые отклонения от нормализованной кривой дают противодействующую фотовольтаическую электродвижущую силу (фотоэдс).

ном $p^{+}-n^{+}$-переходе. В случае дополнительной инжекции (образец $C$ ) фотогенерированный ток увеличивается за счет фотонов, поглотившихся в инжектирующем базовом $p-n$-переходе (в случае образца $C$ это GaInP $p-n$-переход). Далее детально рассмотрено поведение BAX межгенераторных частей и $V_{o c}-J_{g}$-характеристик всего прибора.

\section{1. Образец $A$}

Экстрагированная ВАХ межгенераторной части имеет горб, который происходит от туннельного $p-n$-перехода (рис. 2, a, левая часть, символы). Высота горба (превышение пикового тока над током долины) составляет $\sim 25 \mathrm{~A} / \mathrm{cm}^{2}$ и является наивысшей по сравнению с остальными образцами. Горб не наблюдается в образце $B$, а для образца $C$ высота горба равна $\sim 5 \mathrm{~A} / \mathrm{cm}^{2}$. Горб незначительно $\left(\sim 5 \mathrm{~A} / \mathrm{cm}^{2}\right)$ сдвигается „вниз“ (в сторону меньших токов) при увеличении освещенности, что свидетельствует о малой величине противодействующего фотогенерированного тока. На соответствующей $V_{o c}-J_{g}$-характеристике (рис. 3, треугольники) это отражается в виде отклонения от нормализованной линии (рис. 3, штриховая линия) при $J_{g} \approx 25 \mathrm{~A} / \mathrm{cm}^{2}$. Это значение соответствует высоте горба на экстрагированной ВАХ. Схожее соответствие есть и на остальных образцах.

\section{2. Образец $B$}

Здесь нет вырождения $n$-области туннельного $p^{+}-n^{+}$перехода (рис. 1, $b$, большой круг), поэтому $\mathrm{BAX}$ межгенераторной части не имеет горба (рис. $2, b$, левая сторона), что приводит к большому дифференциальному сопротивлению в нулевой точке. Поэтому противодействующая фотоэдс велика (до 0.6 В), несмотря на то что фотогенерированный ток так же мал, как и в образце A. Как следствие, ВАХ визуально смещается вправо (в сторону меньших напряжений) при увеличении освещенности (жирная стрелка на рис. $2, b$ ). На соответствующей $V_{o c}-J_{g}$-характеристике (рис. 3 , кривая $B$ ) это проявляется в том, что отклонение от нормализованной кривой (от штриховой линии) начинается при меньшем фотогенерированном токе $\left(\sim 0.8 \mathrm{~A} / \mathrm{cm}^{2}\right)$. Соответственно максимум расположен при меньшем $J_{g}\left(\sim 2 \mathrm{~A} / \mathrm{cm}^{2}\right)$.

\section{3. Образец $C$}

Здесь в межгенераторной части отсутствует барьер (рис. $1, c$, большой круг), который есть в образцах $A$ и $B$ (рис. $1, a, b$, окрестность левых пунктирных вертикальных линии) и который препятствует диффузионной инжекции носителей из соседнего прямосмещенного GaInP $p-n$-перехода. Отсутствие барьера приводит к значительному увеличению фотогенерированного тока в туннельном $p^{+}-n^{+}$-переходе из-за дополнительного вклада наведенного тока из GaInP $p-n$-перехода (рис. $1, c$, овал со стрелкой). Поэтому при увеличении освещенности горб значительно (по сравнению с образцами $A$ и $B$ ) сдвигается вниз: на $\sim 30 \mathrm{~A} / \mathrm{cm}^{2}$ против $\sim 3-5 \mathrm{~A} / \mathrm{cm}^{2}$ (рис. 2, $c$, жирная стрелка). Отметим, что когда пиковая точка пересекает нулевую ось тока, то на соответствующей $V_{o c}-J_{g}$-характеристике происходит резкий скачок (рис. 3, точки $c_{1}$ и $c_{2}$ ).

\section{4. Свойства межгенераторной части МП СЭ}

Итак, на свойства межгенераторной части влияют, во-первых, потенциально фотоактивный туннельный гетеро- $p^{+}-n^{+}$-переход и, во-вторых, разделительный потенциальный барьер, образованный изотипным гетероинтерфейсом. Наличие встречной фотоэдс в верхней межгенераторной части $\mathrm{GaInP} / \mathrm{GaAs} / \mathrm{Ge} \mathrm{C} Э$ влияет на $V_{o c}-J_{g}$-характеристику. Вид этой характеристики зависит от свойств формируемого туннельного диода. При этом даже при высоком пиковом токе, при определенной кратности падающего излучения, встречная фотоэдс проявит себя на $V_{o c}-J_{g}$-характеристике. Это наблюдалось ранее в работе [8].

\section{5. Заключение}

Как известно, в трехпереходных GaInP/GaAs/Geсолнечных элементах может наблюдаться противодействующий фотовольтаический эффект. Локализация соответствующего источника внутри трехпереходного солнечного элемента определена в данной работе путем сопоставления трех типов двухпереходных GaInP/GaAs-солнечных элементов, отличающихся устройством межгенераторной части, в которую входит 
туннельный $p^{+}-n^{+}$-переход. Из полных $\mathrm{BAX}$ двухпереходных солнечных элементов были экстрагированы BAX рассматриваемой межгенераторной части. Метод экстрагирования основан на интерпретации нормализованной $V_{o c}-J_{g}$-зависимости как безрезистивной темновой $\mathrm{BAX}$, из которой можно сформировать набор безрезистивных световых ВАХ. Сравнивая последние с экспериментальными световыми ВАХ, можно экстрагировать световые BAX межгенераторной части. Именно их вид и зависимость от освещенности свидетельствуют о существовании противодействующего фотовольтаического эффекта. Наличие горба и его движение в направлении, противоположном движению $J_{s c}$, указывает, что эффект возникает в туннельном гетеро- $p^{+}-n^{+}$-переходе $p^{+}-\mathrm{Al}_{0.4} \mathrm{Ga}_{0.6} \mathrm{As}(\mathrm{C}) / n^{+}-\mathrm{GaAs}(\mathrm{Si})$. Эффект можно минимизировать, во-первых, регулируя высоту барьера, препятствующего диффузионной инжекции в туннельный $p^{+}-n^{+}$-переход из прямосмещенного GaInP $p-n$-перехода. Во-вторых, уменьшая дифференциальное сопротивление туннельного $p^{+}-n^{+}$-перехода.

Было экспериментально показано, что такой эффект проявляется на $V_{o c}-J_{g}$-зависимости при значении фотогенерированного тока близком к пиковому току туннельного диода. В предельном случае (когда отсутствует пиковый ток и вместо туннельного диода образуется обращенный) он проявляется намного раньше (в эксперименте, приведенном в данной работе, эффект наблюдался при токе около $\left.1 \mathrm{~A} / \mathrm{cm}^{2}\right)$. Влияние эффекта на $V_{o c}-J_{g}$-характеристику следующее: сначала она отклоняется от линейного роста в полулогарифмическом масштабе, потом наблюдается максимум и резкое падение напряжения. В случае обращенного диода резкое падение отсутствует.

\section{Конфликт интересов}

Авторы заявляют, что у них нет конфликта интересов.

\section{Список литературы}

[1] P.T. Chiu, D.C. Law, R.L. Woo, S.B. Singer, D. Bhusari, W.D. Hong, A. Zakaria, L. Boisvert, S. Mesropian, R.R. King, N.H. Karam. Proc. 40th IEEE PV Specialist Conf. (2014) p. 11.

[2] F. Dimroth, C. Baur, A.W. Bett, W. Kostler, M. Meusel, G. Strobl. 4 th World Conf. on Photovoltaic Energy Conversion (Waikoloa, HI, 2006) p. 1777.

[3] P. Patel, D. Aiken, D. Chumney, A. Cornfeld, Y. Lin, C. Mackos, J. McCarty, N. Miller, P. Sharps, M. Stan. 38 th IEEE Photovoltaic Specialists Conf. (Austin, TX, 2012).

[4] M.A. Mintairov, N.A. Kalyuzhnyy, V.V. Evstropov, V.M. Lantratov, S.A. Mintairov, M.Z. Shvarts, V.M. Andreev, A. Luque. J. Photovolt., 5 (4), 1229 (2015).

[5] M. Stevens, C. Downs, D. Emerson, J. Adler, S. Maclachlan T.E. Vandervelde. Proc. 31 PVSEC (Hamburg, Germany) (Sept. 14-18, 2015) p. 1474.

[6] J.F. Geisz, A. Duda, M.R. France, D.J. Friedman, I. Garcia, W. Olavarria, J.M. Olson, M.A. Steiner, J.S. Ward, M.Young. AIP Conf. Proc., 1477, 44 (2012).
[7] M.A. Mintairov, V.V. Evstropov, M.Z. Shvarts, S.A. Kozhukhovskaia, S.A. Mintairov, N.A. Kalyuzhnyy. AIP Conf. Proc., Freiburg (Germany), 1766, 050005 (2016).

[8] M.A. Mintairov, V.V. Evstropov, N.A. Kalyuzhnyy, S.A. Mintairov, N.Kh. Timoshina, M.Z. Shvarts. AIP Conf. Proc., Aix-lesBains (France), 1679, 050007 (2015).

[9] R. Varache, C. Leendertz, M.E. Gueunier-Farret, J. Haschke, D. Muñoz, L. Korte. Sol. Energy Mater. Solar Cells, 141, 14 (2015).

Редактор Г.А. Оганесян

\section{Counteracting photovoltaic effect in top intergenerator part of GalnP/GaAs/Ge solar cells}

\author{
M.A. Mintairov, V.V. Evstropov, S.A. Mintairov, \\ M.Z. Shvarts, N.A. Kalyuzhnyy \\ loffe Institute, \\ 194021 St. Petersburg, Russia
}

Abstract Abstract In this paper, the „top“ intergenerator part located between the GaInP and GaAs subcells (generators) has been analyzed. The IV-curves and $V_{o c}-J_{s c}$ (open circuit voltage-shortcircuit current) dependences shapes have been investigated. It has been established that the tunnel hetero $p^{+}-n^{+}$junction, located in the „top“ intergenerator part, can work as a photoelectric source, counteracting the base $p-n$ junctions. In this case, the $V_{o c}-J_{s c}$ characteristic has a dropping part, including a sharp jump. This undesirable effect decreases with increasing peak current. 